\title{
PEMENUHAN GURU PRODUKTIF SMK DI ERA REVOLUSI INDUSTRI 4.0
}

\section{(FULFILLING THE PRODUCTIVE TEACHER OF VOCATIONAL SCHOOL IN INDUSTRY REVOLUTION 4.0 ERA)}

\author{
Jonni Sitorus*, Muhammad Kaulan Karima**, Beta Rapita Silalahi*** \\ *Badan Penelitian dan Pengembangan Provinsi Sumatera Utara \\ Jl. Sisingamangaraja No. 198 Medan 20126 \\ Sumatera Utara - Indonesia \\ Email: sitorus_jonni@yahoo.co.id \\ **Sekolah Tinggi Ilmu Tarbiyah Al Ittihadiyah \\ Jl. Madrasah Islamiyah, Lintas Sumatera No. 210 Gunting Saga, Kabupaten Labuhanbatu Utara \\ Sumatera Utara - Indonesia \\ *** Universitas Muslim Nusantara Al Washliyah Medan \\ Jalan Garu II A, Harjosari I Medan Amplas, Kota Medan 20147 \\ Sumatera Utara - Indonesia
}

Diterima: 10 Desember 2020; Direvisi: 18 Januari 2021; Disetujui: 09 Maret 2021

\begin{abstract}
ABSTRAK
Tujuan penelitian adalah mendeskripsikan kondisi eksisting guru SMK dan pemenuhan guru produktif SMK di era revolusi industri 4.0, baik secara kuantitatif maupun kualitatif. Penelitian merupakan kualitatif dengan pendekatan deskriptif. Penelitian dilakukan di 4 (empat) kabupaten/kota, yaitu: Tebing Tinggi, Pematangsiantar, Medan, dan Deli Serdang. Hasil penelitian menunjukkan bahwa \% jumlah guru produktif SMK dari jumlah seluruh guru di masing-masing SMKN/S tidak merata, yaitu antara 35\% - lebih 50an\%. Hampir semua SMK mengalami kekurangan guru produktif, kecuali: SMKN 1 Pematangsiantar; SMKS Ar-Rahman Medan; dan, SMKN 3 Tebing Tinggi. Jumlah kekurangan guru produktif SMK tidak merata, yaitu antara 2 sampai 26 orang. Pemenuhan kuantitas guru produktif SMK di Sumatera Utara memiliki 10 pola, yaitu: Pengangkatan guru dari Program CPNS; Pengangkatan guru melalui Ikatan Dinas D3 Jakarta; Guru yang pernah mengikuti Program Keahlian Ganda; Pengangkatan guru melalui Program Alih Fungsi pegawai; Pengangkatan guru melalui Guru Tidak Tetap (GTT) Provinsi; Pengangkatan guru melalui GTT yang dibiayai SPP; Pengangkatan guru melalui GTT yang dibiayai Dana BOS; Pengangkatan guru sebagai Guru Tetap Yayasan; Pengangkatan guru melalui Program magang mahasiswa PPG; dan Program Guru Tamu. Program Magang Mahasiswa PPG; Program Penyetaraan Guru; Program Keahlian Ganda; dan Program Guru Tamu, telah bertransformasi sebagai tuntutan revolusi industri 4.0. Pemenuhan kualitas guru produktif SMK di Sumatera Utara memiliki 5 pola, yaitu peningkatan kompetensi guru melalui: pemanfaatan SIM GPO/PKB; aktif di Forum MGMP/KKG; pelatihan; magang di industri; dan kolaborasi dengan Industri, Kelima pola tersebut telah bertransformasi sesuai tuntutan revolusi industri 4.0. Direkomendasikan untuk mengeluarkan Peraturan Gubernur atau Surat Keputusan Bersama dalam rangka kerjasama dan fasilitasi guru magang di industri, guru berkolaborasi dengan Dunia Usaha Dunia Industri (DUDI), pelatihan di DUDI, guru tamu, dan Prakerin Siswa SMK di DUDI, yang dalam regulasi tersebut melibatkan beberapa OPD teknis, misalnya: Dinas Perindustrian dan Perdagangan, Dinas Koperasi dan UKM, Dinas Tenaga Kerja, Dinas Pendidikan, sesuai Tugas dan Fungsi masing-masing OPD.
\end{abstract}

Kata kunci: pemenuhan guru, Guru produktif, SMK, revolusi industri

\section{ABSTRACT}

The research objective is to describe the existing conditions of SMK teachers and the fulfillment of productive vocational teachers in the era of the industrial revolution 4.0 , both quantitatively 
and qualitatively. This is a qualitative research with a descriptive approach. It was conducted in 4 districts/cities, namely: Tebing Tinggi, Medan, Pematangsiantar, and Deli Serdang. The results showed that the\% number of productive vocational teachers from the total number of teachers in each SMKN / $S$ is not evenly distributed, namely the range between 35\% - more than 50\%. Almost all SMK schools experience a shortage of productive teacher, exception of SMKN 1 Pematangsiantar, SMKS Ar Rahman Medan, dan SMKN 3 Tebing Tinggi. The fulfillment of the Productive Teachers quantity at vocational school in North Sumatra has 11 patterns, namely: Teacher Recruitment Program from CPNS Program; D3 Jakarta Program; Dual/Transfer Skill Program; Function Transfer Program; Provincial Honorarium Teacher; Teacher honored from tuition; Teacher honored form school operational costs; Foundation Teacher; Student Apprenticeship Program; and Visiting Teacher Program. Teacher Apprenticeship Program, Teacher Equalization Program; Dual/Transfer Skill Program; and Visiting Teacher Program have been transformed as the demands of the 4.0 industrial revolution. There are 5 patterns of fulfilling the quality of Productive Teachers for vocational school, namely: the use of SIM GPO/PKB; active in MGMP/KKG Forum; training; an internship in industry; and collaboration with Industry. The five patterns have been transformed according to the demands of the 4.0 industrial revolution. It is recommended to issue a Governor Regulation or Joint Decree in the context of cooperation and facilitation for apprentice teachers in industry, teachers collaborating with Business/Industrial World (B/IW), training at (B/IW), guest teachers, and Vocational School Internship in (B/IW), which in this regulation involve several technical Regional Apparatus Organization (RAO), for example: Industry and Trade Office, Cooperatives and Small and Medium Enterprises Office, Manpower Office, Education Office, in according to the Duties and Functions of each RAO.

Keywords: teacher's fulfillment, productive teacher, vocational school, industrial revolution

\section{PENDAHULUAN}

Revolusi industri 4.0 merupakan sistem yang mengintegrasikan dunia online dengan produksi industri dengan penggunaan teknologi digital dan otomatisasi (Prasetyo \& Sutopo, 2018; Merkel, 2017; Schlechtendahl, dkk, 2015; Wurianto, 2018; Hermann, dkk, 2016; Lifter \& Tschieer, 2013). Dunia industri mulai menyentuh dunia virtual artinya dunia tidak nyata, berbentuk konektivitas manusia, mesin dan data. Era revolusi industri 4.0 mengubah konsep dan struktur pekerjaan, serta kompetensi yang dibutuhkan dunia kerja. Era revolusi industri 4.0 juga mengubah cara pandang terhadap konsep pendidikan itu sendiri, salah satunya pendidikan Sekolah Menengah Kejuruan (SMK).

Bukit (2014) menjelaskan bahwa SMK merupakan pendidikan menengah yang berorientasi pada kinerja individu dalam dunia kerja serta pada kebutuhan nyata di lapangan. Tolak ukur keberhasilan SMK tidak hanya terbatas di sekolah, akan tetapi juga pada kepekaan terhadap perkembangan dunia kerja. Kedudukan SMK diperkuat dengan adanya Inpres Nomor 9 tahun 2016 tentang Revitalisasi Sekolah Menengah Kejuruan dalam rangka Peningkatan Kualitas dan Daya Saing Sumber Daya Manusia Indonesia dalam hal peningkatan jumlah dan kompetensi pendidik serta kerjasama dengan Dunia Usaha Dunia Industri (DUDI).

Menurut Waidl (2018), salah satu permasalahan pada pendidikan SMK adalah pemenuhan guru produktif yang jumlahnya tidak sebanding dengan jumlah guru normatif dan adaptif, yaitu 78\% guru SMK merupakan guru normatif-adaptif dan hanya $22 \%$ guru produktif yang mengajar mata pelajaran kejuruan/keteknikan (guru normatif: guru PKN, guru agama, guru Bahasa Indonesia, dan lainlain yang sejenis; guru adaptif: guru fisika, guru $\mathrm{MM}$, guru biologi, guru kimia, dll yang sejenis (Zamtinah, dkk, 2011). Hal ini tentunya tidak sebanding dengan struktur kurikulum SMK, dimana jumlah mata pelajaran keteknikan/kejuruan sebesar 60\% lebih dari jumlah seluruh mata pelajaran yang ada. Artinya bahwa jumlah guru produktif harusnya lebih banyak dari jumlah guru normatif dan adaftif.

Selain kuantitas guru produktif SMK kurang, kualitasnya pun juga minim. Menurut Firdausi \& Barnawi (2012), keterampilan guru untuk mengajar mata pelajaran produktif kurang; beberapa guru SMK belum tahu perkembangan teknologi; kinerja guru kurang maksimal di bidang kompetensi pedagogik, kepribadian, sosial, dan professional; serta tidak banyak guru bersertifikat pendidik yang menguasai mesin/peralatan berbasis teknologi canggih.

Dalam Roadmap Kebijakan Pengembangan Vokasi Indonesia tahun 2017 sampai 2025, pemerintah mencermati beberapa hal: minimnya ketersediaan alat dan guru kejuruan; peran guru dan standardisasi konten pendidikan; tersedianya konten media pendidikan di internet; pengajaran tentang kewirausahaan, inkubasi, dan teaching factory; dan program pemagangan siswa (Afrina, dkk, 2018). Menurut Afriani, beberapa kebijakan mendasar yang harus dilakukan oleh kementerian atau lembaga terkait dalam rangka pengembangan vokasi adalah pemenuhan guru produktif dengan cara membuat aturan agar tenaga pengajar terampil dalam mengajar; peningkatan mutu sarana dan prasarana peralatan praktik yang sesuai dengan kebutuhan 
DUDI; kolaborasi antara lembaga pendidikan vokasi dan DUDI melalui pemagangan; dan memperkuat keterlibatan asosiasi, industri, dan masyarakat dalam pengembangan vokasi.

Menurut Mulyadi (2010), pemenuhan guru produktif SMKN dilakukan dengan berbagai cara, yaitu dengan melakukan redistribusi guru kejuruan dari kota besar ke daerah, melakukan alih kompetensi mengajar guru adaptif/normatif menjadi guru produktif atau melakukan rekruitmen guru produktif baru, dan melakukan KKN tematik bagi mahasiswa pada program keahlian yang relevan dengan SMK.

Menurut Ismara, dkk, (2018), setidaknya ada 3 eleman penting yang harus ditransformasi dalam menjalankan pendidikan SMK di era revolusi industri 4.0, yaitu: sistem pembelajaran yang lebih inovatif seperti penyesuaian kurikulum pembelajaran; rekonstruksi kebijakan kelembagaan pendidikan vokasi yang adaptif dan responsif terhadap revolusi industri 4.0 dalam mengembangkan transdisiplin ilmu dan program studi yang dibutuhkan; dan persiapan sumber daya manusia yang responsif, adaptif dan handal untuk menghadapi revolusi industri 4.0. Selain itu, peremajaan sarana prasarana dan pembangunan infrastruktur pendidikan juga perlu dilakukan untuk menopang kualitas pendidikan.

Berdasarkan penjelasan di atas, penelitian ini bertujuan untuk mendeskripsikan kondisi eksisting guru SMK dan pemenuhan guru produktif SMK di era revolusi industri 4.0, baik secara kuantitatif maupun kualitatif.

\section{METODE}

Provinsi Sumatera Utara memiliki 1.000 SMK, yaitu 268 SMK negeri dan 732 SMK swasta. Penelitian dilakukan di 4 kabupaten/kota, yaitu: Kota Tebing Tinggi, Kota Pematangsiantar, Kota Medan, dan Kabupaten Deli Serdang, dengan nama-nama SMK di masing-masing daerah disajikan pada Tabel 1.

Jenis penelitian adalah kualitatif dengan pendekatan deskripsi, yaitu serangkaian peristiwa terkait pemenuhan guru produktif SMK di era revolusi industri 4.0 di Sumatera Utara. Penelitian tidak semata-mata hanya mementingkan hasil saja, melainkan aspek proses adalah sesuatu yang lebih utama (Bogdan \& Tylor, 1993). Subjek penelitian adalah Kadis, KaCabdis, Kabid, Kasi, kepala sekolah SMK, dan guru SMK. Guru SMK yang dijadikan sebagai subjek penelitian adalah guru produktif SMK, yaitu guru yang mengajar mata pelajaran kejuruan/keteknikan.

Teknik pengumpulan data penelitian menggunakan: 1) observasi, yaitu tim peneliti melakukan pengamatan langsung ke SMK lokasi penelitian. Hal yang diobservasi adalah kondisi fasilitas sekolah, misalnya: laptop, komputer, laboratorium, bengkel, layanan internet, dan lain sebagainya; 2) studi dokumen sekolah berupa: daftar Bidang/Program/Kompetensi keahlian, daftar sarana prasarana sekolah, daftar guru, profil sekolah/Dinas Pendidikan, program dan kegiatan, dokumen kolaborasi SMK dengan DUDI; 3) pengisian kuesioner, yaitu berisi pertanyaan-pertanyaan tentang kegiatan guru/kepala sekolah di era revolusi industri 4.0; dan 4) interview personal, yaitu dengan menggunakan wawancara tidak terstruktur. Halhal yang ditanyakan adalah: kebijakan Pemda/sekolah dalam pemenuhan guru produktif SMK di era revolusi industri 4.0. Data yang bersumber dari hasil wawancara, observasi, dokumen dan kuesioner dianalisis secara kualitatif.

Tabel 1. SMK Negeri dan Swasta sebagai Lokasi Penelitian

\begin{tabular}{|c|c|c|}
\hline No. & Kabupaten/Kota & $\begin{array}{c}\text { Nama SMK } \\
\text { Lokasi Penelitian }\end{array}$ \\
\hline 1. & Tebing Tinggi & $\begin{array}{l}\text { SMKN 2; SMKN 3; } \\
\text { SMKN 4; SMKS } \\
\text { Taman Siswa }\end{array}$ \\
\hline 2. & Pematangsiantar & $\begin{array}{l}\text { SMKN 1; SMKN 2; } \\
\text { SMKN 3; SMKS } \\
\text { Persiapan }\end{array}$ \\
\hline 3. & Medan & $\begin{array}{l}\text { SMKN 8; SMKN 9; } \\
\text { SMKN 13; SMKS Ar } \\
\text { Rahman }\end{array}$ \\
\hline 4. & Deli Serdang & $\begin{array}{l}\text { SMKN } 1 \text { Kutalimbaru; } \\
\text { SMKN } 1 \text { Pancurbatu; } \\
\text { SMKN } 1 \text { Patumbak; } \\
\text { SMKS Istiqlal Deli Tua }\end{array}$ \\
\hline
\end{tabular}

\section{HASIL DAN PEMBAHASAN}

Kondisi Eksisting Jumlah Guru Produktif SMK. Berdasarkan hasil wawancara, dokumen, dan kuesioner, diperoleh data dan informasi terkait kondisi eksisting jumlah guru, baik guru normatif, adaftif, maupun produktif, disajikan pada Tabel 2. Berdasarkan Tabel 2 dapat dijelaskan bahwa \% jumlah guru produktif SMK dari jumlah seluruh guru di masing-masing SMKN/S tidak merata, yaitu kisaran antara 35\% - lebih 50an\%. SMK idealnya memiliki jumlah guru produktif lebih banyak atau minimal $60 \%$ dari jumlah seluruh guru di masing-masing SMK bila merujuk pada struktur kurikulum SMK. Artinya bahwa jumlah guru produktif harusnya lebih banyak dari akumulasi jumlah guru normatif dan adaftif, akan tetapi pada kenyataanya justru berbanding terbalik untuk beberapa SMK sebagaimana dipaparkan pada Tabel 2. 
Tabel 2. Kondisi Eksisting Jumlah Guru SMK

\begin{tabular}{|c|c|c|c|c|c|c|}
\hline \multirow{2}{*}{ No. } & \multirow{2}{*}{ Nama SMK } & \multicolumn{3}{|c|}{$\begin{array}{c}\text { Jumlah Guru SMK } \\
\text { Yang Ada Saat ini (orang) }\end{array}$} & \multirow{2}{*}{$\begin{array}{c}\text { Jumlah Guru } \\
\text { Produktif SMK yang } \\
\text { Ada saat ini dari } \\
\text { Jumlah Seluruh Guru } \\
\text { (\%) }\end{array}$} & \multirow{2}{*}{$\begin{array}{c}\text { Jumlah Guru } \\
\text { Produktif } \\
\text { SMK Yang } \\
\text { Kurang } \\
\text { (orang) } \\
\end{array}$} \\
\hline & & Normatif & Adaftif & Produktif & & \\
\hline \multirow[t]{5}{*}{1.} & Kota Tebing Tinggi & & & & & \\
\hline & SMKN 2 & 17 & 19 & 36 & 50,00 & 2 \\
\hline & SMKN 3 & 11 & 12 & 24 & 51,06 & 0 \\
\hline & SMKN 4 & 27 & 8 & 20 & 36,36 & 7 \\
\hline & SMKS Taman Siswa & 9 & 10 & 12 & 38,71 & 5 \\
\hline \multirow[t]{5}{*}{2.} & Kota Medan & & & & & \\
\hline & SMKN 8 & 26 & 23 & 51 & 51,00 & 20 \\
\hline & SMKN 9 & 28 & 26 & 41 & 43,16 & 26 \\
\hline & SMKN 13 & 21 & 22 & 37 & 46,25 & 22 \\
\hline & SMKS Ar Rahman & 15 & 12 & 17 & 38,64 & 0 \\
\hline \multirow[t]{5}{*}{3.} & Kota Pematangsiantar & & & & & \\
\hline & SMKN 1 & 26 & 11 & 41 & 52,56 & 0 \\
\hline & SMKN 2 & 32 & 30 & 40 & 39,22 & 19 \\
\hline & SMKN 3 & 22 & 23 & 49 & 52,13 & 4 \\
\hline & SMKS Persiapan & 18 & 16 & 20 & 37,04 & 3 \\
\hline \multirow[t]{5}{*}{4.} & Kabupaten Deli Serdang & & & & & \\
\hline & SMKN 1 Patumbak & 16 & 23 & 23 & 37,10 & 13 \\
\hline & SMKN 1 Kutalimbaru & 19 & 27 & 28 & 37,84 & 13 \\
\hline & SMKN 1 Pancurbatu & 7 & 4 & 13 & 54,17 & 13 \\
\hline & SMKS Istiqlal Deli Tua & 42 & 4 & 25 & 35,21 & 12 \\
\hline
\end{tabular}

Sumber: Data Penelitian (2020)

Fenomena lain yang dapat dianalisis dari Tabel 2 di atas adalah ditinjau dari topologi Kota Medan yang merupakan ibukota Provinsi Sumatera Utara, yang secara umum kota ini memiliki jumlah SMK dan guru produktifnya jauh lebih banyak dibanding dengan jumlah SMK dan guru produktifnya di kabupaten/kota lain yang ada di Sumatera Utara. Dengan begitu, secara logika tentunya pihak SMK di Kota Medan akan lebih mudah untuk memenuhi jumlah guru produktif ideal, akan tetapi fakta sebagaimana pada Tabel 2 menginformasikan bahwa 4 SMK lokasi penelitian di Kota Medan memiliki \% jumlah guru produktif di bawah $60 \%$ dari jumlah seluruh guru di masing-masing SMK yang ada. Artinya, pihak SMK di Kota Medan tidak sertamerta dengan mudah untuk memenuhi jumlah guru produktif ideal.

Tabel 2 menggambarkan bahwa hampir semua SMK mengalami kekurangan guru produktif kecuali, SMKN 1 Pematangsiantar, SMKS Ar Rahman Medan, dan SMKN 3 Tebing Tinggi. Jumlah kekurangan guru produktif SMK tidak merata, yaitu kisaran antara 2 sampai 26 orang. Jumlah kekurangan guru produktif SMK di atas merujuk pada kondisi eksisting jumlah guru produktif SMK saat ini saat penelitian dilakukan yaitu tahun 2020, dan belum mempertimbangkan jumlah guru produktif yang akan pensiun tahun depannya. Misalnya: SMKN 2 memiliki 4 (empat) guru produktif yang mendekati masa pensiun tahun ini. Artinya bahwa dari jumlah guru produktif yang ada saat ini tentunya akan berkurang sebanyak 4 orang di tahun ini, sehingga jumlah kekurangan guru produktif tentunya bertambah 4 (empat) orang guru produktif untuk tahun depan.

Berdasarkan hasil wawancara dengan beberapa kepala sekolah dan guru SMK diperoleh informasi bahwa kendati SMK kekurangan banyak guru produktif, akan tetapi proses belajar mengajar tetap berjalan sebagaimana mestinya. Kepala SMK melakukan berbagai cara di lapangan untuk memenuhi guru produktif, diantaranya: pemanfaatan guru lain yang serumpun meskipun kadang keahlian guru tersebut tidak sesuai dengan mata ajar yang diampunya; pengoptimalan jam mengajar guru produktif yang ada sampai 40 jam mengajar per minggu; perekrutan guru baru, dan lain sebagainya.

Kondisi eksisting guru produktif SMK sebagaimana dijelaskan di atas masih dilihat dari beberapa sampel SMKN/S di Sumatera Utara, dan belum melihat kondisi guru produktif di semua SMK di Sumatera Utara, apalagi SMK yang lokasi sekolahnya berada jauh dari ibukota kabupaten/kota atau ibukota kecamatan, yang diperkirakan jauh dari kondisi pemenuhan guru produktif yang mencukupi.

Pemenuhan Kuantitas Guru Produktif SMK di Era Revolusi Industri 4.0. Berdasarkan hasil data dokumen, wawancara, dan kuesioner diperoleh informasi terkait pola pemenuhan kuantitas guru produktif SMK seperti disajikan pada Tabel 3. 
Tabel 3. Pola Pemenuhan Kuantitas Guru Produktif SMK

\begin{tabular}{|c|c|c|c|c|c|c|c|c|c|c|c|c|c|c|c|c|c|}
\hline \multirow{3}{*}{ No. } & \multirow{3}{*}{ Pola Pemenuhan Guru Produktif } & \multicolumn{16}{|c|}{ Jumlah Guru Produktif (orang) } \\
\hline & & \multicolumn{4}{|c|}{$\begin{array}{c}\text { Kota } \\
\text { Medan }\end{array}$} & \multicolumn{4}{|c|}{$\begin{array}{c}* \text { Kota } \\
\text { P.siantar }\end{array}$} & \multicolumn{4}{|c|}{$\begin{array}{c}\text { Kota } \\
\text { T.Tinggi }\end{array}$} & \multicolumn{4}{|c|}{$\begin{array}{l}\text { Kab. Deli } \\
\text { Serdang }\end{array}$} \\
\hline & & 1 & 2 & 3 & 4 & 1 & 2 & 3 & 4 & 1 & 2 & 3 & 4 & 1 & 2 & 3 & 4 \\
\hline 1. & Pengangkatan guru dari Program CPNS & 36 & 19 & 4 & - & $\sqrt{ }$ & $\sqrt{ }$ & $\sqrt{ }$ & - & 31 & 19 & 15 & - & 10 & 3 & 11 & 1 \\
\hline 2. & Pengangkatan guru melalui Ikatan Dinas D3 Jakarta & 4 & - & - & - & - & - & - & - & - & - & - & - & - & - & - & \\
\hline 3. & $\begin{array}{l}\text { Guru yang pernah mengikuti Program Keahlian } \\
\text { Ganda/Alih Keahlian }\end{array}$ & 1 & - & - & - & 2 & 1 & 3 & - & 9 & 4 & 3 & - & - & - & 3 & - \\
\hline 4. & $\begin{array}{l}\text { Pengangkatan guru melalui Program Alih Fungsi } \\
\text { pegawai umum }\end{array}$ & - & - & - & - & 1 & - & - & - & - & - & - & - & - & - & - & - \\
\hline 5. & $\begin{array}{l}\text { Pengangkatan guru melalui Guru Tidak Tetap (GTT) } \\
\text { Provinsi }\end{array}$ & 5 & 14 & 7 & - & 8 & 29 & 10 & - & 5 & 4 & - & - & 4 & 5 & 6 & - \\
\hline 6. & $\begin{array}{l}\text { Pengangkatan guru melalui GTT yang dibiayai } \\
\text { Sumbangan Pembinaan Pendidikan (SPP) }\end{array}$ & 10 & 7 & 23 & 6 & 4 & & 9 & - & - & 1 & - & - & 9 & 6 & 5 & 15 \\
\hline 7. & $\begin{array}{l}\text { Pengangkatan guru melalui GTT yang dibiayai Dana } \\
\text { BOS }\end{array}$ & - & - & 3 & - & 6 & & & - & - & - & - & - & 1 & - & - & 10 \\
\hline 8. & $\begin{array}{l}\text { Pengangkatan guru sebagai Guru Tetap Yayasan } \\
\text { (Guru Swasta yang sertifikasi berasal dari sekolah } \\
\text { yang bersangkutan) }\end{array}$ & - & - & - & 11 & - & - & - & $\sqrt{ }$ & - & - & - & - & - & - & - & - \\
\hline 9. & $\begin{array}{l}\text { Pengangkatan guru melalui Program magang } \\
\text { mahasiswa PPG (Pendidikan Profesi Guru) }\end{array}$ & - & - & 4 & - & - & - & - & - & - & - & - & - & - & 2 & - & - \\
\hline 10. & Program Guru Tamu & $\sqrt{ }$ & $\sqrt{ }$ & $\sqrt{ }$ & - & - & $\sqrt{ }$ & $\sqrt{ }$ & $\sqrt{ }$ & $\sqrt{ }$ & $\sqrt{ }$ & $\sqrt{ }$ & - & $\sqrt{ }$ & $\sqrt{ }$ & $\sqrt{ }$ & $\sqrt{ }$ \\
\hline
\end{tabular}

Sumber: Data Penelitian (2020)

Keterangan:

Tidak ada;

Kota Medan

1. SMKN 8

2. SMKN 9

3. SMKN 13

4. SMKS Ar Rahman

$\begin{array}{ll}\sqrt{ }=\text { Ada } \quad * \text { Sumber data hanya dari hasil wawancara } \\ \text { Kota Pematangsiantar } & \text { Kota Tebing Tinggi } \\ \text { 1. SMKN } 1 & \text { 1. SMKN 2 } \\ \text { 2. SMKN } 2 & \text { 2. SMKN 3 } \\ \text { 3. SMKN 3 } & \text { 3. SMKN 4 } \\ \text { 4. SMKS Persiapan } & \text { 4. SMKS Taman Siswa }\end{array}$

Kabupaten Deli Serdang

1. SMKN 1 Patumbak

2. SMKN 1 Pancurbatu

3. SMKN 1 Kutalimbaru

4. SMKS Istiqlal Deli Tua
Pertama, pengangkatan guru baru melalui Program CPNS. Cara ini merupakan pola lama pemenuhan kuantitas guru di sekolah, yang tidak hanya untuk guru produktif SMK akan tetapi juga di semua tingkatan baik di SD, SMP, SMA, maupun SMK. Pola pemenuhan ini tentu bukan sesuatu yang ideal. Pemerintah terkendala dengan adanya moratorium pegawai negeri. Andaikan ada pengangkatan guru baru, jumlahnya pun juga akan sangat terbatas, sehingga kebutuhan sekolah umumnya sangat tidak sebanding dengan jumlah formasi yang ada. Hal ini mendorong untuk bisa segera memenuhi kekurangan guru produktif SMK dengan menerapkan kebijakan-kebijakan baru lainnya.

Berdasarkan hasil wawancara diperoleh informasi bahwa ujian CPNS dinilai hanya menguji pengetahuan calon guru saja, sementara untuk menjadi seorang guru tidak cukup hanya memiliki pengetahuan akan tetapi juga memiliki keterampilan yang dapat diuji melalui praktek mengajar. Asesmen rekrutmen guru melalui program CPNS perlu ditambah untuk menguji kompetensi dan keterampilan mengajar CPNS formasi guru. Program CPNS dinilai hanya dapat memenuhi sebagian kuantitas guru produktif, akan tetapi kurang terhadap pemenuhan kualitas guru produktif.
Guna meningkatkan keterampilan mengajar, khususnya guru yang baru lulus CPNS, yang notabenanya guru tersebut belum/kurang pengalaman mengajar, maka perlu dilakukan Program Induksi bagi guru pemula, yaitu kegiatan orientasi, pelatihan di tempat kerja, pengembangan, dan praktik pemecahan berbagai permasalahan dalam proses pembelajaran dan bimbingan dan konseling bagi guru pemula pada SMK di tempat tugasnya.

Kedua, Program Keahlian Ganda/Alih Keahlian. Salah satu upaya pemerintah untuk memenuhi kuantitas guru produktif di SMK untuk program jangka pendek yang dinilai sangat efektif dan efisien adalah program keahlian ganda, yaitu seorang guru memiliki 2 atau lebih keahlian dalam mengajar sekaligus, misalnya: seorang guru mengajar mata pelajaran IPA (keahlian sebelum mengikuti Program Keahlian Ganda), sekaligus mengajar mata pelajaran Tata Boga, Tata Kecantikan, atau Tata Busana (keahlian baru pasca Program Keahlian Ganda). Sedangkan Program Alih Keahlian adalah guru hanya beralih keahlian ke keahlian lain dari Jenis Kelompok Keahlian yang sama. Si guru hanya memiliki 1 keahlian mengajar, yaitu keahlian yang baru pasca dilakukan Program Alih Keahlian. Misalnya si guru beralih keahlian dari Multimedia ke Rekayasa Perangkat Lunak. 
Kedua keahlian "Multimedia dan Rekayasa Perangkat Lunak" berasal dari 1 Jenis Kelompok Keahlian yang sama yaitu Teknologi Komputer dan Informatika.

Program Keahlian Ganda memberikan pembekalan pengetahuan dan keterampilan kompetensi keahlian baru bagi guru produktif. Penambahan pembekalan pengetahuan dan keterampilan produktif baru yang dibutuhkan SMK diberikan kepada guru-guru normatif, adaptif, dan produktif dengan tingkat kejenuhan sangat tinggi (jumlah lebih) melalui Program Sertifikasi Keahlian dan Sertifikasi Pendidik bagi Guru SMK/SMA (Keahlian Ganda). Guru adaptif, normatif, dan produktif di SMA dan SMK yang kelebihan guru diberikan tambahan pengetahuan dan keterampilan kompetensi keahlian baru melalui pendidikan dan pelatihan di Pusat Pengembangan dan Pemberdayaan Pendidik dan Tenaga Kependidikan (P4TK).

Ketiga, Program Alih Fungsi Pegawai Umum menjadi Pegawai Fungsional (guru). Berdasarkan data pada Tabel 4 di atas bahwa SMKN 1 Pematangsiantar memiliki 1 guru produktif yang berasal dari pegawai umum. Berbeda halnya di SMKN 3 Pematangsiantar yang justru berbanding terbalik. Menurut guru produktif SMKN 3 Pematangsiantar bahwa ada beberapa guru yang ingin beralih profesi dari fungsional guru menjadi pegawai umum. Hal ini tentunya menjadi ancaman akan keberadaan jumlah guru produktif yang sampai saat ini dirasa masih kurang.

Keempat, Pengangkatan Guru Tidak Tetap (GTT). GTT dibagi menjadi 3 kategori berdasarkan sumber penggajian dan pengSK-an guru, yaitu: 1) GTT Provinsi, yaitu guru honorer yang diangkat oleh Gubernur melalui SK Kepala Dinas Pendidikan Provinsi Sumatera Utara, dan gajinya diberikan berdasarkan Keputusan Gubernur Sumatera Utara. GTT Provinsi merupakan usulan daerah tahun 2017, sementara pengangkatan GTT Provinsi sampai tahun 2020 diberhentikan; 2) GTT yang dibiayai dari SPP, yaitu guru honorer yang diangkat oleh kepala sekolah melalui SK Kepala Sekolah, dan besaran gaji diberikan berdasarkan keputusan dan kesepakatan Komite Sekolah; dan 3) GTT Dana BOS, yaitu guru honorer yang diangkat oleh kepala sekolah melalui SK Kepala Sekolah, dan sumber gaji berasal dari Dana BOS berdasarkan keputusan dan kesepakatan Kepala Sekolah.

Terkait pemberhentian pengangkatan GTT Provinsi, berdasarkan Peraturan Pemerintah Nomor 19 tahun 2017 tentang Perubahan PP Nomor 74 tahun 2008 tentang Guru, pada pasal 59 ayat 3 menyebutkan bahwa pemerintah daerah wajib mengisi kekosongan guru demi kelangsungan proses belajar mengajar, sementara pada UU Nomor 5 tahun 2014 tentang Aparatur Sipil Negara pada Pasal 6 disebutkan bahwa jenis pegawai ASN hanya PNS dan Pegawai Pemerintah dengan Perjanjian Kerja (PPPK). PPPK merupakan pegawai ASN yang diangkat sebagai pegawai dengan perjanjian kerja oleh Pejabat Pembina Kepegawaian sesuai dengan kebutuhan Instansi Pemerintah dan ketentuan Undang-Undang. Artinya bahwa UU Nomor 5 tahun 2014 tentang ASN tidak mengenal pegawai honor atau GTT. Pro dan kontra pada 2 regulasi tersebut menjadikan beberapa Pemerintah Daerah, termasuk Provinsi Sumatera Utara menghentikan pengangkatan GTT Provinsi, bahkan beberapa Pemerintah Daerah lainnya berencana memberhentikan GTT tersebut.

Berdasarkan hasil wawancara bahwa tidak semua guru honor dapat digaji dari Dana BOS. Berdasarkan Peraturan Menteri Pendidikan dan Kebudayaan Nomor 8 Tahun 2020 tentang Petunjuk Teknis Bantuan Operasional Sekolah Reguler bahwa pembiayaan pembayaran honor diberikan kepada guru yang berstatus bukan aparatur sipil negara dan harus memenuhi persyaratan sebagai berikut: 1) tercatat pada Data Pokok Pendidikan (Dapodik) per 31 Desember 2019; 2) belum mendapatkan tunjangan profesi; dan, 3) memenuhi beban mengajar termasuk mengajar dari rumah dalam masa penetapan status Kedaruratan Kesehatan Masyarakat Covid-19 yang ditetapkan Pemerintah Pusat. Permasalahannya adalah bahwa beberapa guru produktif SMK belum masuk ke daftar Dapodik, sehingga tidak bisa digaji dari Dana BOS.

Kelima, Program Guru Tamu, yaitu program kolaborasi mengajar bagi guru SMK yang mengajar mata pelajaran produktif di SMK pada kompetensi keahlian yang mempunyai karakteristik tertentu. Kriteria guru tamu yang layak dijadikan sebagai narasumber dalam pembelajaran, yaitu: memiliki pendidikan minimal tamatan Sekolah Teknik Menengah/Sekolah Menengah Kejuruan; telah bekerja minimal 5 tahun dibidangnya; industri/perusahaan/bengkel tempat narasumber bekerja tergolong maju; mampu untuk membimbing siswa, orang ini biasanya ditempatkan dibagian training atau kepala mekanik dari suatu industri/perusahaan/bengkel tempatnya bekerja; telah terjalin kerjasama antara sekolah dengan institusi tempatnya bekerja, misalnya dalam hal Praktek Kerja Industri (Prakerin), magang siswa dan sebagainya.

Firdaus (2018) dalam penelitiannya menyatakan bahwa guru tamu adalah orang luar 
(bukan guru) yang memberikan pelajaran kepada siswa sesuai dengan keahlian dan keterampilan yang dimilikinya. Orang luar ini diharapkan memiliki keahlian khusus misalnya ahli teknik mesin atau perbengkelan otomotif yang relevan dengan mata pelajaran mekanik otomotif. Pembelajaran dengan memanfaatkan guru tamu dapat dilakukan dengan 2 cara, yakni orang tersebut (narasumber) diminta untuk memberikan penjelasan tentang sesuatu secara teori dan praktek di depan kelas dan di bengkelbengkel atau workshop sekolah; dan/atau siswa-siswa melakukan kunjungan ke tempat narasumber bekerja di bawah pengawasan dan bimbingan para guru.

Pola pemenuhan guru produktif SMK melalui Program Guru Tamu merupakan salah satu cara merealisasikan Inpres Nomor 9 tahun 2016 tentang Revitaliasi SMK, yang telah dilakukan sejak tahun 2016 sampai sekarang. Artinya bahwa pola ini merupakan pola baru, yaitu baru dilakukan di era revolusi industri 4.0, di atas tahun 2011. Pola ini merupakan salah satu bentuk dan cara bertransformasi dalam rangka pemenuhan kuantitas guru produktif SMK di era revolusi industri 4.0.

Ketujuh, Program Magang Mahasiswa PPG (Pendidikan Profesi Guru). Program ini merupakan program pendidikan yang diselenggarakan untuk mempersiapkan lulusan S1 Kependidikan dan Nonkependidikan yang memiliki bakat dan minat menjadi guru agar menguasai kompetensi guru secara utuh sesuai dengan standar nasional pendidikan sehingga dapat memperoleh sertifikat pendidik profesional. PPG terdiri dari PPG dalam Jabatan dan PPG Prajabatan. PPG dalam jabatan merupakan program dimana peserta yang mengikuti program tersebut telah menjadi guru pada satuan pendidikan. Sedangkan PPG Prajabatan merupakan program dimana peserta yang mengikuti program tersebut belum menjadi guru atau sudah menjadi guru namun tidak memenuhi syarat menjadi peserta PPG dalam jabatan.

Berdasarkan hasil wawancara bahwa Program Mahasiswa Magang PPG dilakukan hanya 1 gelombang oleh Kemendikbud, dan terdapat sekitar 500an peserta di seluruh Indonesia untuk ikut berpartisipasi. Penempatan para mahasiswa magang PPG guru yang sudah lulus sampai saat ini tidak jelas. SMKN 13 Kota Medan memiliki 4 guru produktif yang berasal dari Program Mahasiswa Magang PPG. Menurut pihak SMKN 13 bahwa para guru yang ikut Program Mahasiswa Magang PPG dijanjikan akan diangkat menjadi guru PNS oleh pihak panitia magang PPG, akan tetapi sampai saat ini status para guru tersebut tidak jelas.
Pola pemenuhan guru produktif SMK melalui Program Magang Mahasiswa PPG merupakan salah satu cara untuk merealisasikan UU Nomor 14 tahun 2005 tentang Guru dan Dosen. Pola ini menerapkan sistem pendidikan guru yang mengintegrasikan proses perkuliahan dan pengenalan lapangan sedini mungkin melalui magang (internship). Mahasiswa PPG memiliki pengalaman nyata dan kontekstual dalam menerapkan seperangkat pengetahuan, sikap, dan keterampilan yang dapat menunjang tercapainya penguasaan kompetensi pedagogik, kompetensi kepribadian, kompetensi sosial, dan kompetensi penguasaan materi bidang studi secara utuh. Pola ini merupakan salah satu bentuk dan cara bertransformasi dalam rangka pemenuhan kuantitas guru produktif SMK di era revolusi industri 4.0 .

Pemenuhan Kualitas Guru Produktif SMK di Era Revolusi Industri 4.0 Berdasarkan hasil wawancara, dokumen, kuesioner diperoleh data dan informasi terkait pemenuhan kualitas guru produktif SMK, disajikan pada Tabel 4.

Pertama, Program Belajar Mandiri melalui Sistem Informasi Manajemen Terpadu Guru Pembelajar Online (SIM GPO) atau Sistem Informasi manajemen Pengembangan Keprofesian Berkelanjutan (SIM PKB). Sejak tahun 2017 lalu, Ditjen GTK sudah mengembangkan program SIM PKB yang menjadi kelanjutan dari SIM GPO, dengan tujuan untuk meningkatkan kompetensi guru yang sudah terintegrasi dalam SIM PKB.

SIM GPO/PKB adalah suatu sistem informasi manajemen terpadu/berkelanjutan yang dibuat oleh Pemerintah khusus untuk guru untuk meningkatkan kualitasnya. Pemerintah membuat satu sistem online, dimana guru dapat mengaksesnya secara online dengan menggunakan Guru Pembelajar Id melalui https://gurupembelajar.id.

Belajar mandiri dilakukan melalui 3 (tiga) moda, yaitu: 1) tatap muka, merupakan pembelajaran dengan interaksi langsung antarfasilitator dengan peserta. Moda ini diperuntukkan bagi guru yang tidak bisa mengikuti pembelajaran moda lain karena alasan geografis, tidak/kurang tersedianya aliran listrik dan jaringan internet, ketersediaan anggaran, literasi teknologi informasi dan komunikasi, serta alasan lain yang rasional, dengan mempelajari 8-10 modul; 2) moda Daring, yaitu pembelajaran yang memanfaatkan teknologi jaringan komputer dan internet, dengan mempelajari 3-5 modul; dan 3) moda Daring kombinasi, yaitu moda yang mengkombinasikan antara tatap muka dengan Daring, dengan mempelajari 6-7 modul. 
Direktorat Kemitraan dan Penyelarasan Dunia Usaha dan Dunia Industri, Direktorat Jenderal Pendidikan Vokasi Kemendikbud membuat terobosan 2 program baru sebagai menu pada sistem SIM GPO (SIM PKB sebutan saat ini), yaitu Program upskilling dan reskilling guru SMK. Program upskilling adalah peningkatan kemampuan guru dan reskilling adalah pelatihan kemampuan baru bagi para guru. Kemendikbud membuka kesempatan bagi 2.160 orang guru untuk mengikuti program upskilling dan reskilling guru kejuruan SMK. SMK harus mampu beradaptasi dengan pembelajaran yang fleksibel dan kontekstual dengan industri melalui pemanfaatan perkembangan teknologi di industri yang cepat dengan skema pembelajaran project by learning atau bring industry to school.

Pelaksanaan program upskilling dan reskilling guru kejuruan SMK didasarkan pada pemetaan 4 bidang cluster center of excellence (CoE) SMK, meliputi bidang: manufaktur dan konstruksi, ekonomi kreatif, hospitality, dan care service. Pemilihan $\mathrm{CoE}$ tersebut telah mempertimbangkan tren perkembangan industri dan kapasitas penyerapan tenaga kerja. Secara total, terdapat 21 kompetensi keahlian di SMK yang masuk dalam kriteria. Program upskilling dan reskilling guru kejuruan SMK dilakukan secara pembelajaran daring dan pembelajaran campuran sesuai dengan kompetensi dan keterampilan kejuruan yang akan dicapai guru. Pelatihan dilakukan selama 2 sampai 4 bulan bagi guru SMK yang memiliki usia di bawah 50 tahun dan memiliki Nomor Unik Pendidik dan Tenaga Kependidikan (NUPTK).

Hal baru yang mengalami transformasi pada pola belajar mandiri di era revolusi industri 4.0 ini adalah pemanfaatan moda (sarana belajar) untuk belajar mandiri bagi guru. Sebelum era revolusi industri 4.0, guru belajar mandiri dengan menggunakan moda tatap muka, yaitu interaksi secara langsung antara fasilitator dengan peserta pembelajaran, sedangkan di era revolusi industri 4.0 ini, selain moda tatap muka, guru juga menggunakan moda Daring dan Daring kombinasi.

Kedua moda ini merupakan cara belajar mandiri bagi guru dengan memanfaatkan fasilitas internet dan teknologi digital melalui komputer, laptop, HP, atau sejenisnya. Pemanfaatan media internet pada pola belajar mandiri melalui moda Daring dan Daring kombinasi merupakan tuntutan kompetensi guru di era revolusi industri 4.0.

Menurut Nurkholis dan Badawi (2019), salah satu kompetensi yang harus dimiliki oleh guru di era revolusi industri 4.0 adalah kompetensi mendidik atau pembelajaran berbasis internet of thing sebagai basic skill. Guru tentunya harus dapat mengoperasikan komputer di era saat ini. Guru juga harus menguasai internet karena di era saat ini internet sudah menjadi kebutuhan primer dalam kehidupan. Guru akan tertinggal oleh waktu bila tidak bisa internet dan komputer.

Tabel 4. Pola Pemenuhan Kualitas Guru Produktif SMK

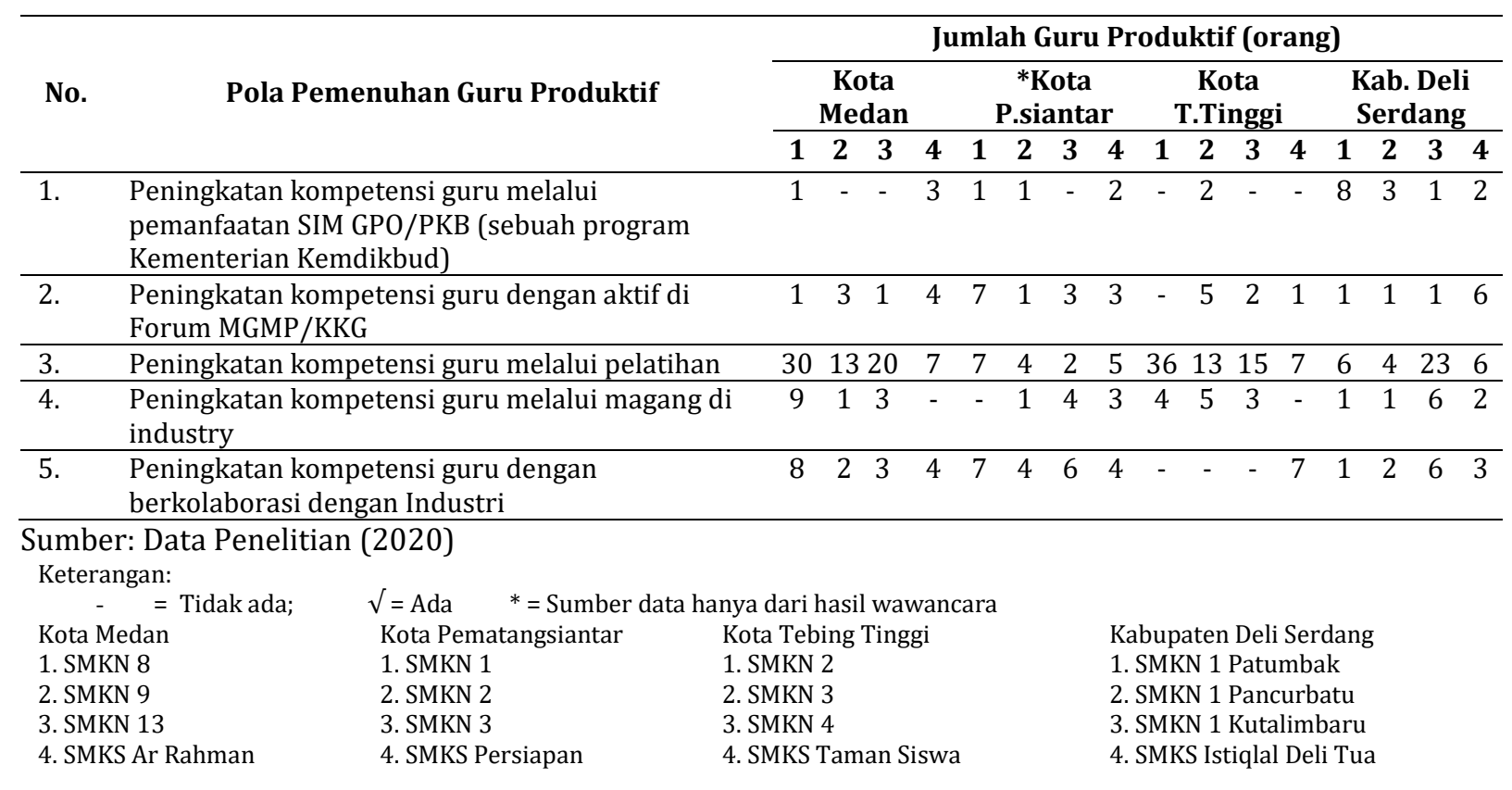


Kedua, Forum Musyawarah Guru Mata Pelajaran (MGMP) dan Kelompok Kerja Guru (KKG). Forum MGMP/KKG adalah suatu wadah asosiasi atau perkumpulan bagi guru mata pelajaran yang berada di suatu sanggar, kabupaten/kota yang berfungsi sebagai sarana untuk saling berkomunikasi, belajar, dan bertukar pikiran dan pengalaman dalam rangka meningkatkan kinerja guru. Adapun beberapa materi diskusi di Forum MGMP/KKG yang pernah diikuti oleh beberapa guru produktif adalah: penggunaan teknologi untuk peningkatan kompetensi guru, pemanfaatan google classroom dalam pembelajaran Daring, materi-materi keteknikan, misalnya: teknik komputer dan jaringan Casco, perhotelan dan tata kecantikan, dan lain sebagainya.

Hal baru yang mengalami transformasi pada kegiatan MGMP/KKG di era revolusi industri 4.0 ini adalah materi diskusi yaitu pemanfaatan teknologi digital dan e-literasi, serta materi-materi keteknikan/kejuruan. Transformasi kegiatan MGMP/KKG di era revolusi industri 4.0 ini merupakan kegiatan guru dengan memanfaatkan fasilitas internet, eliterasi, serta teknologi digital melalui komputer, laptop, HP, atau sejenisnya. Pemanfaatan media internet, teknologi digital serta e-literasi merupakan tuntutan kompetensi guru di era revolusi industri 4.0.

Ketiga, Program Pelatihan, yaitu sebuah sarana untuk meningkatkan keterampilan kerja guru produktif SMK agar sesuai dengan standar yang diharapkan oleh DUDI. Pelatihan yang dilakukan oleh Lembaga Penjamin Mutu Pendidikan (LPMP) umumnya hanya untuk guru normatif dan adaptif, sedangkan pelatihan untuk guru produktif SMK umumnya dilakukan oleh P4TK.

Salah satu pelatihan yang pernah diikuti oleh guru produktif adalah pelatihan keahlian tata boga di P4TK bidang Bisnis dan Pariwisata, Sawangan-Bogor yaitu Pengolahan Aneka Makanan Indonesia, Asia, dan Kontinental; Pelayanan Makan dan Minum di Restoran; Pengolahan Aneka Kue Indonesia dan alain sebagainya. Beberapa guru produktif SMKN 9 Medan telah mengikuti berbagai jenis pelatihan, yaitu sistem jaringan, programming website, mikrotek, dan fiber optik. Beberapa guru produktif SMKN 13 Medan telah mengikuti pelatihan SCADA (Supervisory Control and Data Acquisition) pada Program Mahasiswa Magang PPG untuk jurusan Teknik Otomasi Industri. SCADA merupakan sistem kendali industri berbasis komputer yang dipakai untuk pengontrolan suatu proses industri. Beberapa guru produktif SMKS Ar-Rahman Medan telah mengikuti pelatihan ACCURATE untuk jurusan Akuntansi.

Hal baru yang mengalami transformasi kegiatan pelatihan di era revolusi industri 4.0 ini adalah bahwa pelatihan tidak hanya pada pengetahuan pedagogis saja akan tetapi juga keterampilan kerja sesuai ilmu pengetahuan dan teknologi yang diterapkan di industri di era globalisasi saat ini. Menurut Irwanto (2019) bahwa salah satu kompetensi yang dibutuhkan guru vocational di era revolusi industri 4.0 adalah memiliki kompetensi yang sesuai dengan di DUDI, yang dapat mengorganisasikan dan memadukan pembelajaran baik teori maupun praktik.

Keempat, Program Magang di Industri, yaitu dilakukan dengan beberapa metode: modeling, approximating, scaffolding, self directed learning dan generalisasi. Magang guru dapat meningkatkan relevansi kompetensi keahlian guru produktif dengan perkembangan Iptek di DUDI. Guru dapat melihat secara nyata tamatan seperti apa yang dicari dan dibutuhkan oleh DUDI. Guru dapat mengetahui kompotensi mana yang harus dipertajam dalam pembelajaran agar dapat melahirkan peserta didik yang kompeten sesuai dengan kompetensi yang dibutuhkan. Magang guru dapat menambah pengetahuan dan keterampilan yang mendukung guru produktif SMK untuk lebih aktual pada saat mengajar dan memperoleh gambaran bagaimana prosedur kerja di DUDI.

Berdasarkan hasil wawancara bahwa pihak sekolah tidak memiliki anggaran biaya bagi guru yang melakukan magang. Biaya tersebut untuk kebutuhan akomodasi guru, biaya makan selama magang, uang saku guru, operasional magang, dll. Dalam berbagai kebijakan, Program Magang Guru merupakan langkah srategis Direktorat Pembinaan SMK- Kemendikbud, yang dituangkan dalam Permendikbud Nomor 26 tahun 2017 tentang Petunjuk Teknis Bantuan Operasional Sekolah (BOS).

\section{... biaya untuk magang guru di industri sebanyak 5 kali dalam setahun, yang meliputi biaya akomodasi, transportasi dan/atau uang saku.}

Pada Permendikbud di atas dijelaskan bahwa magang guru dilaksanakan dalam bentuk: mengikuti pelatihan kerja di industri; magang di industri untuk menghasilkan uji mutu produk/jasa dalam merealisasi kesepakatan teaching factory; magang di industri untuk menghasilkan bahan baku teaching factory; mengikuti magang di industri dengan tujuan untuk kerjasama dalam rangka memperoleh lisensi; mengikuti pelatihan mendapatkan 
sertifikasi dari industri atau lembaga sertifikasi; dan/atau mengikuti magang kerja untuk menjalin kerjasama dengan industri.

Kelima, kolaborasi guru SMK-praktisi industri, yaitu peningkatan kualitas pembelajaran kejuruan di SMK melalui pemberdayaan karyawan dari DUDI yang berpengalaman untuk mengajar siswa SMK. Terdapat 2 mekanisme pemberdayaan praktisi industri dalam pembelajaran SMK, yaitu melalui perekrutan praktisi industri yang sudah berusia menjelang 50 tahun untuk beralih menjadi guru SMK khusus mapel produktif, dan melalui program kelas industri dimana sekolah menggandeng para praktisi industri untuk melatih para siswa pada mata pelajaran praktek tertentu berkolaborasi dengan guru.

Para praktisi yang sudah lama terjun di industri tentu sudah cukup kaya dengan pengalaman kerja. Pengalaman dan keterampilan kerja di DUDI tersebut menjadi bekal yang sangat baik untuk mengajar di SMK. Didukung kondisi psikologis diusia yang telah matang menjadikan mereka lebih siap dalam membimbing siswa. Perekrutan guru dari praktisi industri atau disebut guru produktif menjadi solusi untuk meningkatkan kompetensi siswa SMK sehingga memiliki daya saing tinggi. Pembelajaran produktif yang melibatkan instruktur dari industri dilaksanakan melalui team teaching. Guru dan praktisi industri bersama-sama melaksanakan pembelajaran. Praktisi industri fokus pada transfer keterampilan produktif, sedangkan guru mensupervisi dari sisi pedagogisnya. Selain itu, ketika guru berkolaborasi dalam pembelajaran bersama praktisi industri, guru sekaligus dapat terus mengupgrade pengetahuan dan keterampilannya dengan belajar dari praktisi industri.

\section{KESIMPULAN}

Persentase jumlah guru produktif SMK dari jumlah seluruh guru di masing-masing SMKN/S tidak merata, yaitu kisaran antara 35\% - lebih 50an\%. Hampir semua SMK mengalami kekurangan guru produktif kecuali, SMKN 1 Pematangsiantar, SMKS Ar Rahman Medan, dan SMKN 3 Tebing Tinggi. Jumlah kekurangan guru produktif SMK tidak merata, yaitu kisaran antara 2 sampai 26 orang per SMK.

Pemenuhan kuantitas guru produktif SMK di Sumatera Utara memiliki 10 pola, yaitu: Pengangkatan guru dari Program CPNS; Pengangkatan guru melalui Ikatan Dinas D3 Jakarta; Guru yang pernah mengikuti Program Keahlian Ganda/Alih Keahlian; Pengangkatan guru melalui Program Alih Fungsi pegawai umum; Pengangkatan guru melalui Guru Tidak
Tetap (GTT) Provinsi; Pengangkatan guru melalui GTT yang dibiayai SPP; Pengangkatan guru melalui GTT yang dibiayai Dana BOS; Pengangkatan guru sebagai Guru Tetap Yayasan; Pengangkatan guru melalui Program magang mahasiswa PPG; dan Program Guru Tamu.

Pemenuhan kualitas guru produktif SMK di Sumatera Utara memiliki 5 pola, yaitu peningkatan kompetensi guru melalui: pemanfaatan SIM GPO/PKB; aktif di Forum MGMP/KKG; pelatihan; magang di industri; dan kolaborasi dengan Industri.

\section{REKOMENDASI}

1. Gubernur Sumatera Utara agar Mengeluarkan Peraturan Gubernur atau Surat Edaran Gubernur atau Surat Keputusan Bersama antara Gubernur dengan DUDI dalam rangka kerjasama dan fasilitasi guru magang di industri, guru berkolaborasi dengan DUDI, pelatihan di DUDI, guru tamu, dan Prakerin Siswa SMK di DUDI, yang dalam regulasi tersebut melibatkan beberapa OPD teknis, misalnya: Dinas Perindustrian dan Perdagangan, Dinas Koperasi dan UKM, Dinas Tenaga Kerja, Dinas Pendidikan, sesuai Tugas dan Fungsi masing-masing OPD.

2. Kepala Dinas Pendidikan Provinsi Sumatera Utara agar: berkoordinasi dengan BKD untuk melakukan Program Induksi bagi guru pemula yang baru lulus CPNS sebelum penempatan mengajar di SMK; Melakukan Program Keahlian Ganda berdasarkan kebutuhan jenis paket keahlian guru produktif dari guru-guru adaptif SMA yang berlebih untuk dialihtugaskan ke unit SMK yang kekurangan guru produktif; Memetakan kebutuhan pelatihan guru produktif SMK berdasarkan Jenis Paket Keahlian SMK; Menyusun Petunjuk Teknis Operasional (PTO) pelaksanaan kegiatan pelatihan bagi guru-guru produktif SMK dalam bentuk Keputusan Kepala Dinas; Menggandeng Dinas Koperasi, UKM, dan Perindustrian Perdagangan dalam rangka pekerjaaanpekerjaan yang dapat dikerjasamakan, misalnya: kolaborasi SMK dengan DUDI yang harus melibatkan Dinas Koperasi, UKM, dan Perindustrian Perdagangan sebagai OPD yang bersentuhan langsung dengan perusahaan sesuai Tusinya.

3. Kepala Dinas Koperasi, UKM, dan Perindag. Provinsi Sumatera Utara agar: memberikan rekomendasi atau surat pengantar untuk diajukan ke industri tempat magang guru atau Prakerin siswa yang mau dituju agar dapat meminimalisir penolakan; Melibatkan/mengundang guru-guru produktif dalam rangka Pelatihan Marketing 
dan Transaksi secara online dan pengembangan UMKM Digital.

4. Kepala Sekolah SMK agar Memanfaatkan alumni SMK yang telah bekerja di DUDI untuk dijadikan sebagai guru tamu ke sekolah dengan memperhatikan ketentuan dan syarat yang berlaku untuk meminimalisir pengeluran biaya honor guru tamu;

5. Pengawas Sekolah SMK agar Menyusun, memperbaharui, dan memetakan materi diskusi MGMP/KKG yang fokus dan menyentuh tentang kejuruan/keteknikan sesuai kebutuhan SMK pada program pembimbingan dan pelatihan profesional guru produktif SMK.

6. Guru Produktif SMK agar: Menerapkan pengalaman bekerja di DUDI ke proses belajar mengajar di kelas melalui penyampaian materi pelajaran sesuai kebutuhan nyata di lapangan dan berorientasi pada kinerja individu di dunia kerja, serta peka terhadap perkembangan dunia kerja; Memanfaatkan teaching factory atau factory to classroom di Ruang Praktik Sekolah sebagai pengganti magang di industri untuk meningkatkan keterampilan kerja berbasis industri; serta, menjalin hubungan kerjasama antara guru dengan DUDI melalui pendekatan hubungan emosional.

\section{UCAPAN TERIMA KASIH}

Penulis mengucapkan terima kasih kepada Badan Penelitian dan Pengembangan Provinsi Sumatera Utara yang telah membiayai kegiatan penelitian ini.

\section{DAFTAR PUSTAKA}

Afrina, E., Rahayu, D., Harja, I. T., Muhammad, R., Zunivar, A. Y., Ramdlaningrum, H., \& Lauranti, M. 2018. Vokasi di Era Revolusi Industri: Kajian Ketenagakerjaan di Daerah. Jakarta: Perkumpulan Prakarsa.

Bukit, M. 2014. Strategi dan Inovasi Pendidikan Kejuruan dari Kompetensi ke Kompetisi. Bandung: Alfabeta.

Firdaus. 2018. Manfaat Guru Tamu untuk Meningkatkan Hasil Belajar Kelas XI Teknik Sepeda Motor SMK YPTN Bangkinang Kota. Jurnal Pendidikan Tambusai. 2(1).

Firdausi, A. \& Barnawi. 2012. Profil Guru SMK Profesional. Jogjakarta: Ar-Ruzz Media.

Hermann, M., Pentek, T., \& Otto, B. 2016. Design Principles for Industrie 4.0 Scenarios. The 49th Hawaian International Conference on Systems Science.

Inpres Nomor 9 Tahun 2016 tentang Revitalisasi Sekolah Menengah Kejuruan dalam rangka
Peningkatan Kualitas dan Daya Saing Sumber Daya Manusia Indonesia.

Irwanto. 2019. Kompetensi Guru Vokasional SMK di Era Revolusi Industri 4.0. Prosiding Seminar Nasional Pendidikan FKIP, Vol. 2, No.1, 2019, hal. 182-204. Universitas Sultan Ageng Tirtayasa.

Ismara, K. I., Fitrihana, N., Amaripuja, P., Danupranata, G., Nadzir, M., Raharjo, A. B., \& Widadi, S. 2018. Buku Referensi Cyberzone: Membangun Bisnis di Era Industri 4.0. Jakarta: Direktorat Pembinaan Sekolah Menengah Kejuruan.

Liffler, M., \& Tschiesner, A. 2013. The Internet of Things and the Future of Manufacturing. McKinsey \& Company.

Merkel, A. 2017. Speech by Feeral Chancellor Angela Merkel to the OECD Conference. [Online] Dari: http;/www.bundesregierung,de/Contect/EN/Raden/ 2014/2014-02-19-oecdmerkel paris_en.html, [Diakses 20 Februari 2020].

Mulyadi. 2010. Diagnosis Kesulitan Belajar \& Bimbingan Terhadap Kesulitan Belajar Khusus. Yogyakarta: Nuha Litera.

Nurkholis, Anwar, \& Badawi. 2019. Profesionalisme Guru di Era Revolusi Industri 4.0. Prosiding Seminar Nasional Pendidikan Program Pascasarjana Universitas PGRI Palembang, 12 Januari 2019.

Peraturan Pemerintah Republik Indonesia Nomor 19 tahun 2005 tentang Standar Nasional Pendidikan.

Peraturan Menteri Pendidikan dan Kebudayaan Nomor 8 tahun 2020 tentang Petunjuk Teknis Bantuan Operasional Sekolah Reguler.

Peraturan Menteri Pendidikan dan Kebudayaan Nomor 26 Tahun 2017 tentang Petunjuk Teknis Bantuan Operasional Sekolah.

Prasetyo, H., \& Sutopo, W. 2018. Industri 4.0: Telaah Klasifikasi Aspek dan Arah Perkembangan Riset. Jurnal Teknik Industri, Vol. 13, No. 1, Hal. 17-26.

Schlechtendahl, J., Kretschmer F. M., Lechler, A., \& Verl, A. 2015. Making Existing Production Systems Industry 4.0-Ready. Production Engineering, 9(1) hal: 143-148.

Undang-Undang Nomor 14 tahun 2005 tentang Guru dan Dosen.

Waidl, A., Wardana, K., \& Ni'mah, S. K. 2018. Kertas Kebijakan, Enam Rekomendasi Kebijakan Pelatihan Vokasi: Urgensi Pelatihan Vokasi Inklusif dengan Melibatkan Serikat Pekerja, Masyarakat Sipil, serta Pelaku Usaha Kecil dan Menengah di Indonesia. International NGO Forum of Indonesian Development.

Wurianto, A. B. 2018. Pengembangan Pendidikan Vokasi Bidang Sosio-Humaniora Menghadapi Revolusi Industri Era 4.0. Prosiding Seminar Nasional Vokasi Indonesia, Volume 1, e-ISSN 2654-6493.

Zamtinah., Kurniawan, U., Sarosa, D., \& Tyasar., R. 2011. Model Pendidikan Karakter untuk Sekolah Menengah Kejuruan. Jurnal Pendidikan Karakter. 1(1) hal: 98-109. 